\title{
Combination of compressed sensing and parallel imaging with respiratory motion correction for highly-accelerated cardiac perfusion MRI
}

\author{
Ricardo Otazo ${ }^{*}$, Daniel Kim, Leon Axel, Daniel K Sodickson \\ From 2011 SCMR/Euro CMR Joint Scientific Sessions \\ Nice, France. 3-6 February 2011
}

\section{Introduction}

Cardiac perfusion MRI requires fast data acquisition to achieve an appropriate combination of temporal resolution, spatial resolution and spatial coverage for clinical studies [1]. We have recently presented a combination of compressed sensing and parallel imaging ( $k$-t SPARSESENSE) to highly accelerate perfusion studies [2]. However, this method is sensitive to respiratory motion, which decreases temporal sparsity and produces temporal blurring in the reconstructed images. In this work, we present a rigid respiratory motion correction method which allows highly-accelerated first-pass cardiac perfusion MRI to be performed without strict breath-holding.

\section{Purpose}

To develop a respiratory motion correction method for joint compressed sensing and parallel imaging acceleration of first-pass cardiac perfusion MRI.

\section{Methods}

Free-breathing first-pass cardiac perfusion MRI with 0.1 $\mathrm{mmol} / \mathrm{kg}$ of Gd-DTPA (Magnevist) was performed using a modified multi-slice TurboFLASH pulse sequence. Healthy volunteers were imaged on a whole-body $3 \mathrm{~T}$ scanner (Siemens; Tim-Trio) using the standard 12element body matrix coil array. The relevant imaging parameters include: $F O V=320 \mathrm{~mm} \times 320 \mathrm{~mm}$, image resolution $=1.7 \mathrm{mmx} 1.7 \mathrm{~mm}$, slice-thickness $=8 \mathrm{~mm}, \mathrm{TE} /$ $\mathrm{TR}=1.3 / 2.5 \mathrm{~ms}$, repetitions $=40$. An acceleration factor of 8 was used to acquire 10 slices per heartbeat with temporal resolution of $60 \mathrm{~ms} / \mathrm{slice}$. Data undersampling was performed using a pseudo-random ky-t pattern [2].
Fully-sampled low-resolution coil sensitivity reference data were acquired in the first heartbeat. Image reconstruction was performed in two-steps using the $\mathrm{k}-\mathrm{t}$ SPARSE-SENSE algorithm [2] with temporal FFT as sparsifying transform. First, an intermediate k-t SPARSESENSE reconstruction is generated for respiratory motion correction. Rigid motion between frames is detected by computing the displacement of each frame from this intermediate $k-t$ SPARSE-SENSE reconstruction with respect to the coil sensitivity reference using a crosscorrelation approach in the image domain [3]. Second, motion correction is performed by aligning all the frames in the accelerated data. The final k-t SPARSESENSE reconstruction is computed using the aligned accelerated data.

\section{Results}

Rigid respiratory motion correction significantly increased sparsity in the temporal Fourier domain, which is due to better alignment among frames (Fig. 1). Fig. 2 shows $k$-t SPARSE-SENSE reconstruction of a representative slice from the free-breathing perfusion scan without and with motion correction. The utilization of motion correction decreased temporal blurring and presented images with higher quality.

\section{Conclusions}

This work demonstrates feasibility of highly-accelerated first-pass cardiac perfusion MRI without strict breathholding with rigid respiratory motion correction. Future work will explore the use of non-rigid motion correction. The proposed technique may be useful for imaging patients with impaired breath-hold capabilities.

New York University School of Medicine, New York, NY, USA 

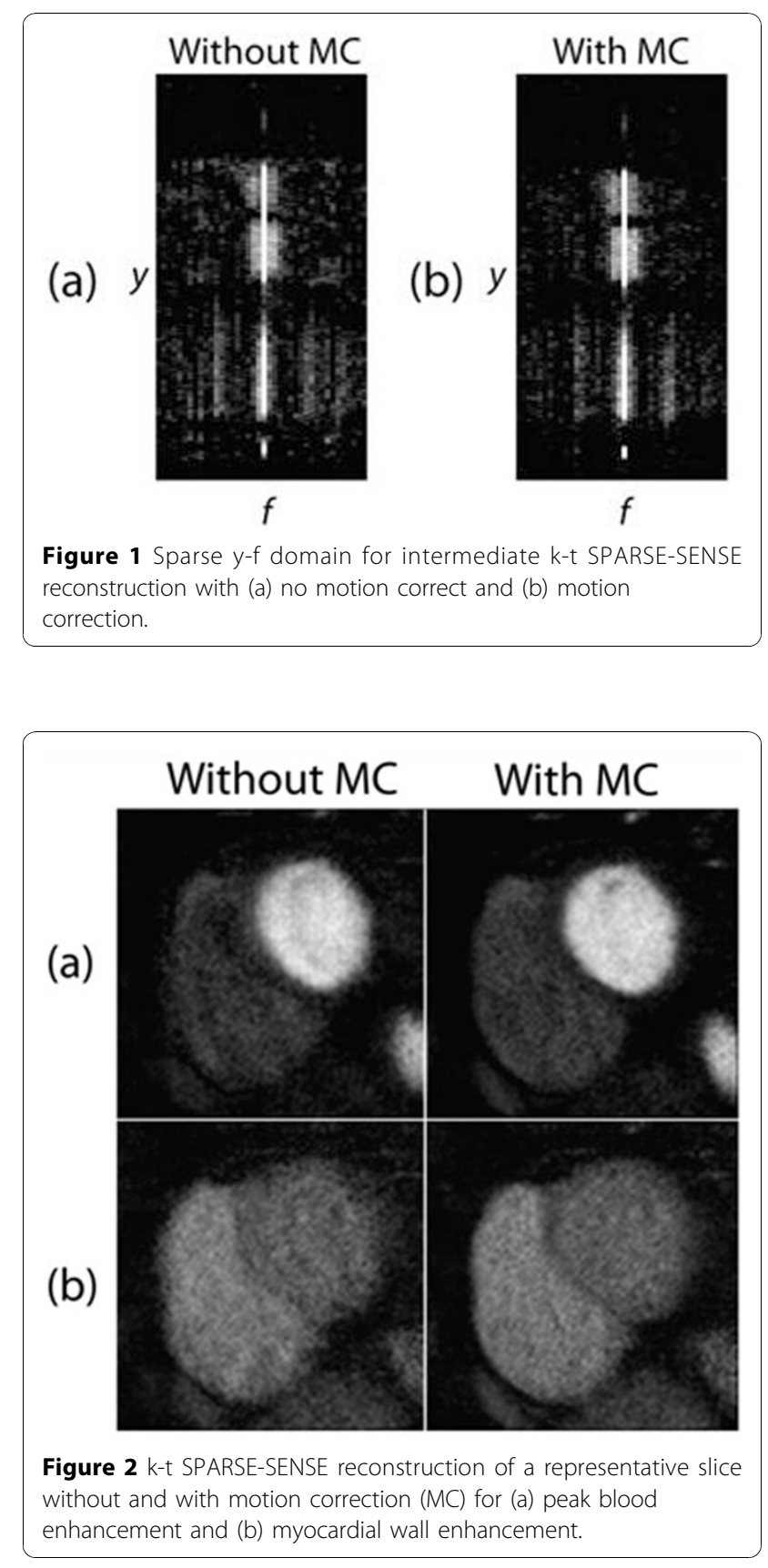

Published: 2 February 2011

\section{References}

1. Kellman P, et al: J Cardiovasc MR 2007, 9(3):525-537.

2. Otazo, et al: Magn Reson Med 2010, 64(3):767-776.

3. Makela T, et al: IEEE Trans Med Imag 2002, 21(9):1011-1021.

doi:10.1186/1532-429X-13-S1-098

Cite this article as: Otazo et al:: Combination of compressed sensing and parallel imaging with respiratory motion correction for highlyaccelerated cardiac perfusion MRI. Journal of Cardiovascular Magnetic Resonance 2011 13(Suppl 1):O98.
Submit your next manuscript to BioMed Central and take full advantage of:

- Convenient online submission

- Thorough peer review

- No space constraints or color figure charges

- Immediate publication on acceptance

- Inclusion in PubMed, CAS, Scopus and Google Scholar

- Research which is freely available for redistribution 